1 Distrito Sanitário Especial Indígena Potiguara, Secretaria Especial de Saúde Indígena - João Pessoa (PB). Ministério da Saúde - Brasília (DF), Brasil.

danieladolpho@gmail.com

2 Universidade Federal de Campina Grande (UFCG)

- Campina Grande (PB),

Brasil.

alvarezalyne@gmail.com

3 Universidade de Brasília (UnB) - Brasília (DF),

Brasil.

torres.tici@gmail.com

\section{Políticas de saúde mental, álcool e outras drogas e de criança e adolescente no Legislativo}

\author{
Mental health, alcohol and other drugs, and child and adolescent \\ policies in the Legislative
}

Daniel Adolpho Daltin Assis', Alyne Alvarez Silva², Ticiana Torres $\mathbf{3}$

RESUMO Após mapeamento dos Projetos de Lei (PL) em trâmite, entre 2003 e 2016, no Congresso Nacional, apresentam-se resultados preliminares oriundos de análise dos PL relacionados com os eixos Álcool e outras Drogas e Infância e Juventude, temas que predominam nas proposituras no campo da saúde mental. No período analisado, observou-se a hegemonia de projetos conservadores em ambos os eixos, pois se distanciam do Sistema Único de Saúde constitucional, em sua maioria propostos por partidos de direita. Do mesmo modo, no âmbito do poder executivo, após o afastamento da Presidenta da República, a migração de parlamentares para assumirem pastas ministeriais pode gerar impactos negativos na Política Nacional de Saúde Mental, Álcool e outras Drogas.

PALAVRAS-CHAVE Poder legislativo. Saúde mental. Criança. Adolescente. Usuários de drogas.

ABSTRACT After mapping the Bills (PL) in progress between 2003 and 2016 at National Congress, we present preliminary results from the analysis of PL related to the axes Alcohol and other Drugs and Childhood and Youth, themes that predominate in the propositions in the mental health field. In the analyzed period, we observed the hegemony of conservative bills, in both axes, for they move away from the constitutional Unified Health System (SUS), mostly proposed by right-wing parties. Similarly, in the context of the Executive power, after the impeachment of the President of the Republic, the migration of parliamentarians to take ministerial portfolios can generate negative impacts on the National Policy of Mental Health, Alcohol and other Drugs.

KEYWORDS Legislative. Mental health. Child. Adolescent. Drug users. 
1 Adverte-se que a soma não resulta no total numérico apresentado em razão de dois $\mathrm{PL}$ terem sido identificados em ambos os eixos.

\section{Introdução}

No âmbito dos direitos humanos, o Brasil adota, desde os anos 1980, paradigmas que emancipam várias populações do locus de objeto de intervenção ao de sujeito de direitos, entre elas, as crianças e adolescentes e as pessoas que fazem uso de drogas. O primeiro público é elevado ao grau de pessoa com discernimento e, por isso, com direitos garantidos no contorno denominado 'proteção integral', que supera a doutrina da situação irregular, pela qual a essa população reservavam-se apenas deveres disciplinares e correcionais, em contexto de direitos já violados. Já o segundo público entra em novo circuito de cuidados na medida em que, de um lado, é contemplado pela Lei ${ }^{\circ} 10.216 / 01$, apelidada de 'lei da Reforma Psiquiátrica', que dispõe sobre os direitos das pessoas com transtornos mentais (BRASIL, 2001A); de outro, pela Lei $n^{0} 11.343 / 06$, conhecida como 'nova lei de drogas' (BRASIL, 2006A), cuja Política Nacional de Drogas, em parte homônima à de Saúde Mental, despenaliza o crime de uso de substâncias psicotrópicas (ou, conforme se alterna neste artigo, drogas), abolindo a pena privativa de liberdade. A evolução histórica das políticas de saúde mental e dos direitos de crianças e adolescentes apresenta, entre outras evidências, a superação do paradigma da tutela de loucos, usuários de drogas, crianças e adolescentes em direção ao reconhecimento desses públicos como sujeitos de direitos. Um dos pontos de clivagem entre as ações destinadas a esses públicos, a Política Nacional de Saúde Mental, Álcool e outras Drogas reúne um conjunto de programas e ações que visam

reorientar o modelo de atenção psicossocial no sentido da lógica da produção de saúde e do reconhecimento da autonomia dos usuários dos serviços, no âmbito territorial-comunitário, preferencialmente, em meio extra-hospitalar. (ASSIS; SILVA, 2016, P. 170).
O tema das drogas, inclusive no âmbito da infância e adolescência, sedia o convívio entre conquistas e retrocessos constitucionais que vão desde o financiamento de estratégias privadas de atenção (vertente do cuidado) até a ampliação do controle das liberdades (vertente da responsabilização). É o que se pretende apresentar no presente artigo a partir de estudos avaliativos de políticas públicas sociais e criminais e de resultados preliminares da pesquisa Análise de Políticas de Saúde no Brasil (2013 - 2017), no eixo Acompanhamento de Iniciativas do Poder Legislativo Federal em Saúde (OBSERVATÓRIO dE ANÁLISE POLÍtICA EM SAÚDE, 2016). Dada a relevância histórica dos estudos e determinantes sociais que devem fundamentar a construção legislativa das políticas de saúde (BAPTISTA, 2003; FONSECA, 2008), na linha de pesquisa A Saúde Mental na Ação do Legislativo Nacional, do referido eixo, objetivou-se investigar a atuação do poder legislativo nas ações de promoção de saúde mental, de 2003 a 2016.

Como resultado preliminar, encontraram-se 223 Projetos de Lei (PL) propostos, dos quais $139^{1}$ representam os campos de álcool e outras drogas (106) e de infância e adolescência (35), números que demonstram a crescente importância do tema na agenda parlamentar. Desse modo, o elevado número de PL nos dois campos citados justifica a escolha dos eixos temáticos sobre os quais sedebruçam ao longo deste artigo.

\section{Material e métodos}

O levantamento de dados deu-se por meio do uso dos buscadores localizados na primeira página de cada portal dos sites da Câmara dos Deputados e do Senado Federal. O mapeamento fora iniciado pela inserção de expressões-chave nos campos de pesquisa dos documentos. Foram as seguintes expressões utilizadas para garantir um amplo espectro de procura: 'usuário de droga', 
'usuária de droga', 'deficiente mental', 'abuso de droga', 'saúde mental', 'droga', 'substância psicoativa', 'substância ilícita', 'álcool', 'cannabis', 'crack', 'viciad', 'dependência química', 'drogadição', 'transtorno mental', 'internação', 'internação psiquiátrica', 'internação compulsória', 'lei 10.216', 'psiquiatri', 'ECA'; 'infância e juventude'; 'saúde mental'; 'adolescência'.

Após o mapeamento, o processo de análise exigiu um exercício de agrupamento dos PL de cada eixo em torno dos temas a que se referiam, resultando na sua categorização, conforme os objetivos dispostos em suas ementas, o nível de reiteração de seus motes e na quantificação deles. Agrupados por categoria, problematizaram-seseus conteúdos, em termos de suas proposições conservadoras ou progressistas, e seus impactos sobre as populações relacionadas com cada eixo, bem como analisaram-se brevemente os períodos de maior produção legislativa. Cerca de $82 \%$ dos PL, ao final da análise, mostram-se conservadores seja porque alguns reiteram a previsão legal atual, outros reclamam ação meramente punitiva, seja porque há também aqueles se propõem a reduzir o espectro de direitos humanos do próprio público a que se destina sua norma.

Analisaram-se, ainda, as iniciativas a partir das direções partidárias e o lugar dos partidos na correlação de forças institucionais. Uma via eleita de análise foi a quantificação de PL propostos por partidos de esquerda, centro e direita, e, a seguir, a relação do resultado dessa divisão com a classificação de textos progressistas e conservadores. Para a primeira separação, levou-se em conta a classificação realizada pelo Departamento Intersindical de Assessoria Parlamentar (Diap) em dezembro de 2014, de acordo com o qual, são partidos de esquerda PT, PSB, PDT, PCdoB e PSOL; de centro, PMDB, PSDB, PPS, PV e SD; de direita, PRB, PMN, PRP, PRTB, PSDC, PSL e PTC ${ }^{2}$. Atualizada por pesquisa d'O Globo (VASCOCELOS, 2016), em março de 2016, que fragmenta a esquerda em 'esquerda' e 'centro-esquerda', PDT e PSB situam-se na centro-esquerda. Qualificaramse como progressistas os projetos alinhados aos marcos regulatórios de proteção dos direitos humanos, sobretudo da luta antimanicomial, da Reforma Psiquiátrica, do Sistema Único de Saúde (SUS), da política de drogas e de proteção integral de crianças e adolescentes, sendo aqueles fundamentados nas Leis $n^{0} 10.216 / 2001$ (BRASIL, 2001B), 8.080/1990 (BRASIL, 1990B) e 11.343/06 (BRASIL, 2006B); já este último, na Lei no 8.069/1990 (BRASIL, 1990A).

\section{Resultados e discussão}

\section{Eixo Álcool e outras Drogas}

Após a identificação dos PL a partir do uso das expressões-chave citadas, verificou-se o que há em comum em seu conteúdo (especialmente a partir da ementa), posteriormente classificados em 8 categorias temáticas, dentro das quais se distribuíram os 104 PL encontrados da seguinte maneira: 'tratamento'(26), 'prevenção' (23), 'punição' (23), 'reabilitação' (6), 'detecção no trânsito' (6), 'descriminalização’ (2), ‘despenalização' (1) e outros em 'geral'(17), totalizando uma média de 7,5 PL/ ano. Vale explicar que na categoria 'geral' encontram-se todos os PL que se incluemem mais de uma adotada. As oito categorias foram construídas conforme o tema/objetivo predominantemente expresso no texto proposto. Com exceção da categoria 'detecção no trânsito' - a ser comentada adiante -, elas foram classificadas, inicialmente, em dois grandes blocos que contemplariam os projetos de lei: o bloco de temas tipicamente localizados no campo da saúde pública e o bloco cujas expressões orientam as políticas de responsabilização socioeducativa e criminal nas políticas de álcool e outras drogas. Sendo assim, 'tratamento', 'prevenção' e 'reabilitação' conformam ações pilares que coordenam o processo saúde-doença-cuidado e intitulam
$2 \mathrm{Na}$ ordem: Partido dos

Trabalhadores, Partido

Socialista Brasileiro,

Partido Democrático

Trabalhista, Partido

Comunista do Brasil,

Partido Socialismo e

Liberdade, Partido do

Movimento Democrático

Brasileiro, Partido da

Social Democracia

Brasileira, Partido Popular Socialista, Partido Verde,

Solidariedade, Partido

Republicano Brasileiro,

Partido Renovador

Trabalhista Brasileiro,

Partido Social Democrata

Cristão, Partido Social

Liberal, Partido Trabalhista

Cristão. 
3 Inegavelmente, tratase de um intervalo de anos de contrastante investimento orçamentário na Política de Saúde Mental, com especial escopo no cuidado às pessoas com necessidades em saúde pelo uso de drogas. Exemplo disso é a aceleração do investimento em Centros de Atenção Psicossocial (Caps); reajuste do repasse; criação, na portaria Raps, do Caps III AD (Centro de Atenção Psicossocial Álcool e Drogas), destinado ao cuidado diuturno às pessoas que fazem uso de drogas (BRASIL, 2012B) programas estratégicos presentes nos três níveis de complexidade da atenção no SUS.

As categorias 'punição', 'descriminalização’ e ‘despenalização’, por sua vez, são expressões comumente empregadas nas ações de responsabilização dos sujeitos que fazem uso de álcool e outras drogas. Vale dizer que a primeira expressão veicula um pensamento mais conservador na resposta estatal diante do usuário das substâncias, sediando paradigma proibicionista e tutelar que, por si, é polarizado pelas ações de segurança pública, ao contrário das duas outras, que indicam prevalência da abordagem do usuário no campo da saúde pública. A categoria 'descriminalização’ foi forjada no sentido de abarcar os raros e inéditos textos que, na contramão ideológica do maior conjunto de PL encontrados nesta pesquisa, propõem retirar da esfera penal a resposta estatal ao uso de drogas. Também contra-hegemônica, a categoria 'despenalização' merece destaque porque, ainda que não exclua o uso do âmbito penal, dá visibilidade às respostas estatais que não atingem a liberdade do sujeito. Ao contrário das demais categorias nominadas, cujos PL alvejam, exclusivamente, o uso de drogas, criou-se a categoria 'detecção no trânsito' em virtude da incidência estatal de maior rigor punitivo sobre a associação de dois comportamentos: o uso de droga e a condução de veículos automotores, sendo, nos próprios documentos, secundário $\mathrm{o}$ debate sobre a licitude da substância.

Nesse sentido, identificou-se, por ano, a seguinte quantidade de PL (entre parênteses): 2012 (17), 2009 (16), 2011 e 2003 (13), 2016 (11), 2013 (7), 2007 (6), 2010 (5), 2004 (4), 2015, 2006 e 2005 (3), 2014 (2), 2008 (1). Logo, os anos de 2003, 2009, 2011, 2012 e 2016 superam a média anual, dos quais 2012, 2009, 2011 e 2003, nessa ordem, lideram, com larga vantagem, o rol de anos com maior incidência. O que há em comum entre esses anos? Das várias hipóteses possíveis, inclusive a que deve levar em conta a constituição das bancadas em cada legislatura, lança-se, a princípio, a mais óbvia, que diz respeito ao fato de os anos de 2003 e 2011 serem, cada qual, o primeiro ano de mandato legislativo, o que permite supor que a atuação propositiva do parlamentar, imediatamente à sua posse, vise responderao público que o elegeu. Quanto aos outros picos de produção legislativa no campo, é no contexto de produção da demanda de enfrentamento ao crack, que, nos anos de 2009 (Portaria GM/MS $\mathrm{n}^{\mathrm{o}}$ 1.190/09, instituiu o Plano Emergencial de Ampliação do Acesso ao Tratamento e Prevenção em Álcool e outras Drogas no Sistema Único de Saúde, primeiro programa da 'era' de enfrentamento ao crack) (BRASIL, 2009A) e 2012 (ano de vigência real da Portaria GM/MS no 3.088, de 23/12/2011, que institui a Rede de Atenção Psicossocial (Raps), portaria de maior lastro para a Política Nacional de Saúde Mental, Álcool e outras Drogas) (BRASIL, 2011A), o poder legislativo também protagoniza na disputa pelas políticas atuais de atenção às pessoas com necessidades decorrentes do uso de álcool e outras drogas. Aproximando-se ainda mais a lupa sobre esse período, verifica-se que a janela temporal entre 2009 e 2012 fora ocupada por quase metade (51) dos PL propostos durante os 14 anos em análise ${ }^{3}$.

A despeito de a propositura normativa ser uma das duas atribuições parlamentares, o fato de haver picos de produção legislativa não significa, automaticamente, tratar-se de inovações alinhadas à Política Nacional de Saúde Mental e aos paradigmas de direitos humanos. Se, por um lado, a categoria 'prevenção'apresenta PL de fortalecimento das estratégias de redução de danos decorrentes do uso de drogas (ex. PL 6.520/06 e 1.692/07) e incumbência às empresas de álcool e cigarros inscreverem nas embalagens informações sobre formas de cuidados com o uso da substância (ex. PL 983/03, 871/03, 4.391/04, 1.066/07), projetos de lei dessa natureza praticamente desaparecem a partir de 2010, início do 'período crack'. Em contrapartida, é nesse momento que 
também cresceu o número de propostas, na categoria 'punição', de agravamento da pena do crime de consumo, como o Projeto de Lei do Senado/PLS 67/09, que propõe "reforçar a punição prevista para o consumo pessoal de drogas com a imposição cumulativa da pena de multa" (BRASIL, 2009C); o PLS 227/09, que dispõe sobre a "pena de detenção para condutas relacionadas ao consumo pessoal de droga" (BRASIL, 2009C), e o PLS 285/12, que altera a lei para "prever o crime de tráfico econsumo de drogas ilícitas, e dá outras providências" (BRASIL, 2012F). Da mesma forma, a categoria 'tratamento', com constante quantidade de propostas no período dos 14 anos, mas com pico de iniciativas em 2011 e 2012, parece também seguir a tendência do 'período crack': se, nos primeiros anos, eram propostos PL de ampliação da rede de ações e serviços privados e públicos (ex. PL 2.584/03, 1.599/03, 4.938/05, 271/07, 6.684/09 e 6.772/10), a partir de 2010, voltam-se a fortalecer modalidades mais gravosas de intervenção sanitária (principalmente pela imposição da internação psiquiátrica compulsória) em nome da proteção de pessoas que fazem uso de drogas (ex. PL 7.663/10, 1.144/11, 2.372/11, 3.167/12, $3.450 / 12,6.839 / 13)$. Não se pode deixar de mencionar PL progressistas, categorizados como 'descriminalização'e 'despenalização', como o PL 7270/14, que

regula a produção, a industrialização e a comercialização de cannabis, derivados e produtos de cannabis, dispõe sobre o Sistema Nacional de Políticas Públicas sobre Drogas. (BRASIL, 2014A),

e o PL 7187/14, que dispõe sobre

o controle, a plantação, o cultivo, a colheita, a produção, a aquisição, o armazenamento, a comercialização e a distribuição de maconha ('cannabis sativa') e seus derivados. (BRASIL, 2014B).
O caráter progressista se deve à direção contrária de aumento da superpopulação carcerária, desmonopolização da produção clandestina e o deslocamento, no que compete à atuação estatal, da questão do contexto policial para os contextos sanitário e socioassistencial.

O ano de 2016 confirma a tendência, porém contrasta com os demais: é o quinto ano de maior produção legislativa no tema, considerando que a coleta se deu até o mês de agosto; nas categorias, residem prioritariamente propostas eminentemente conservadoras ou de retrocesso. Localizados entre os três anos de maior produção legislativa nessa temática, osmeses de janeiro a agosto de 2016 protagonizamna categoria 'punição' (6 PL, 40\%), seguida pela 'detecção no trânsito'(3 PL), cujos textos vão na contramão dos direitos de liberdade, autonomia e do cuidado em saúde. Naquela categoria, encontram-setrês tipos de textos de teor responsabilizatório: os PL 5.742 e 5.649, que estabelecem o aumento da pena para práticas de crimes em que se influencie a vítima pela oferta de drogas; o PL 5.090, que proíbe a importação de drogas sem autorização legal interna, resta isolado entre o primeiro grupo e o terceiro, cujos PL 5.877 e 5.712 propõem o aumento de pena para crimes de homicídio praticado por condutores sob o efeito do uso de drogas. Ainda, pode-se definir como parte desse grupo o PL 5.298, que, porém, diverge quanto à natureza punitiva, civil, realizada pelaindenização financeira do autor à vítima, o que pode representar uma maneira mais relacional de reparação de dano do que a mera prisão.

Quanto à categoria 'detecção', os PL 6.069 e 5.431 determinam que o motorista profissional se submeta a exames toxicológicos periódicos, mas não necessariamente durante a condução do veículo, o que, portanto, não atinge o resultado esperado, de inibiçãoda condução sob efeito psicoativo. Ainda na mesma categoria, o PL 4.848 impõe que a União custeie as despesas relativas aos 
exames, mesmo que no tocante a um ramo produtivo e laboral específico e privado. Na categoria 'prevenção' (2 PL), o PL 4.380 proíbe o "transporte de passageiro alcoolizado em assento adjacente ao do motorista”, diferentemente do PL 5.020 - único alinhado aos atuais paradigmas de prevenção em saúde -, que propõe a inserção do conteúdo temático no currículo escolar. Percorre-se, assim, uma esteira histórica de PL marcados pelo tema das drogas em cujos textos, de 2003 a 2009, prevalecem ações de construção de serviços e orientações de cuidado, e, de 2009 a 2016, predominam ações de repressão e cerceamento de direitos em nome da proteção. Com isso, torna-se evidente que, no primeiro período, o objeto dos documentos é a política pública; no segundo, é o próprio sujeito o alvo a ser regulado.

\section{Eixo Infância e Juventude}

Para a compreensão do cenário legislativo no âmbito da saúde mental de crianças e adolescentes, durante o levantamento de PL oriundos do mesmo período selecionado (2003 - 2016), organizaram-se os dados relativosaos conteúdos dos PL, às filiações partidárias, ano das proposições, em diálogo com a Política Nacional de Saúde Mental e Política de Direitos de Criança e Adolescente. Considerando esses aspectos, problematizaram-se possíveis implicações sociais desses PL nas políticas citadas.

Após o mapeamento, encontraram-se 35 PL, classificados, de acordo com seu texto, nas seguintes categorias (e a quantidade entre parênteses): 'garantia de direitos' (7), 'proteção' (10), 'responsabilização socioeducativa' (13) e 'medicalização da vida' (5). Adotaram-se essas expressões por serem de comum uso nas bandeiras de defesa dos direitos de crianças e adolescentes: a expressão 'garantia de direitos' intitula o Sistema de Garantia de Direitos (Resolução do Conselho Nacional dos Direitos da Criança e do Adolescente - Conanda $\mathrm{n}^{\mathrm{o}}$
117/2006) (CONANDA, 2006); 'proteção' adjetiva medidas propriamente adotadas com fulcro no Estatuto da Criança e do Adolescente (art. 98) (BRASIL, 1990C), da mesma forma com que ocorre no âmbito da 'responsabilização socioeducativa' (art. 112); a 'medicalização da vida' responde à agenda do Fórum Nacional sobre Medicalização da Educação e da Sociedade (FÓRUM, 2016) e à literatura a seguir utilizada.

Em breve análise do período, o ano em que mais houve proposições foi 2012 (6), seguido por 2011 e 2015 (5), 2003 (4), 2009 e 2010 e 2016 (3), 2004 (2), 2006, 2007, 2008 e 2013 (1). Nota-se, assim, que, tal como no eixo anterior, a maioria (74\%) dos PL em pauta são propostos na segunda metade do período de análise, sendo que, no ano de 2009, inauguram-se os programas voltados ao crack e se intensificam todas as ações de atenção às pessoas com necessidades decorrentes do uso de álcool e outras drogas. Do mesmo modo, a produção de PL, nesse eixo, apresenta pico no período 2009 - 2012 (17). De acordo com o que se apresenta a seguir, é exatamente nessa direção que se propõem os PL, com significativo teor repressivo e tutelar.

No contexto dos PL categorizados como de 'garantia de direitos', trata-se de proposições mais amenas, com tendência a fortalecer as diretrizes de cuidado em saúde mental já existentes, como no PL 4.767/2012, que pretende garantir "assistência integral e multiprofissional à criança e ao adolescente dependentes químicos e/ou com problemas decorrentes do uso de drogas" (BRASIL, 2012A). Mesma direção verifica-se no PL $5.705 / 2016$, que dispõe sobre ações específicas com relação ao "cuidado com a saúde mental dos menores infratores submetidos ao regime de internação" (BRASIL, 2016A). Nesse caso, a ação proposta já é papel dos pontos de atenção da Raps. O mesmo entendimento pode-se extrair da análise do PLS 408/2011, que propõe "assistência médica e psicológica ao adolescente viciado em drogas, bem como promover campanhas sociais de 
prevenção e combate ao uso das mesmas" (BRASIL, 2011B), algo semelhante ao que propõe o PL 6.874/2010, que estabelece a "criação de núcleo psicossocial nas escolas públicas de ensino fundamental" (BRASIL, 2010A). Outro exemplo é o constante do PL 3.121/2012, que, embora misture a condição psicossocial de jovens desempregados e de jovens com necessidades decorrentes do uso de drogas, propõe, para ambos, a criação de "programas de recuperação [...] mediante capacitação técnica ou profissional, ou atendimento médico, psicológico e social” (BRASIL, 2012B). Nesse caso, também se encontram ações específicas voltadas a ambos os grupos de jovens.

Da mesma maneira, as proposições categorizadas como 'proteção' reiteram ações públicas já previstas, como a estabelecida no PL 1.795/2015, que constitui como crime "vender, fornecer, servir, ministrar ou entregar bebida alcoólica e energética a criança ou a adolescente" (BRASIL, 2015A), o que ocorre também com o PL 4.478/2004, PL 6.411/2009, PL 3.158/2004 e o Projeto de Lei da Câmara/PLC no 80/2012, que propõem a mesma medida com relação a produto que cause dependência.

Com outro fim, dois PL tornam tutelares as ações de proteção, com textos que têm como efeito a violação dos direitos de liberdade, intimidade e do dever de sigilo do profissional vinculado à criança ou adolescente. Trata-se do PL 5.933/16, que estabelece a comunicação compulsória de casos de consumo de drogas por crianças e adolescentes a unidades de saúde, e do PL 5.356/16, que, com mesma resposta, impõe a comunicação aos pais e conselho tutelar. É importante pontuar que discursos de garantia de direitos ou de proteção de determinadas populações em situação de vulnerabilidade devem ser analisados com cautela com o fim de demarcar a linha tênue que por vezes separa a proteção e o controle/contenção dos corpos para a gestão biopolítica dos 'desviantes' (FOUCAULt, 2008). Processos de normalização dos considerados 'anormais' - porque questionam a ordem vigente - travestem-se de discursos protetivos em nome da defesa da sociedade, com alta aprovação de grande parte da população, amedrontada diante das diferenças produzidas como resultado de processos políticos desiguais próprios do neoliberalismo. Nesse contexto, narrativas de proteção têm embaraçado a compreensão acerca do processosaúde-doença-cuidado, transformando problemas de saúde em questões criminais.

Ao adentrar nos conteúdos dos PL categorizados como de 'responsabilização socioeducativa', percebe-se que a maioria está relacionada, predominantemente, com diagnósticos psiquiátricos (ex. PL 1.052/2011, que impõe seja o adolescente autor de ato infracional "obrigatoriamente submetido a exame psiquiátrico e a testes projetivos de personalidade" (BRASIL, 2011A), e PL 395/07, que determina a submissão do adolescente autor de ato infracional ao crivo psiquiátrico), tratamento (ex. PL 23/2012, que cria a oitava medida socioeducativa, de "atendimento médico-psiquiátrico, consistente em tratamento ambulatorial ou internação" (BRASIL, 2012D), a despeito de ser esse um direito à saúde) e punição (ex. PL 2.116/2015, que também cria a oitava medida socioeducativa, "medida de segurança", em "regime especial”, "por prazo indeterminado" (BRASIL, 2015B), o que viola os princípios socioeducativos da medida). Por vezes, os conteúdos se misturam, a exemplo do PL 1.325/2015, que determina que laudo psiquiátrico prévio ensejará "internação preventiva" (BRASIL, 2015C), sendo a internação definitiva sem prazo determinado, como também ocorre com os PL 2.588/2003 e 7.208/2010. Tais PL, todos propostos após a nova lei de drogas, têm como público adolescentes que fazem uso abusivo de drogas, de modo que o princípio da brevidade, previsto para a medida socioeducativa de internação, já não responde mais aos anseios de lhes colocar para fora do circuito da proteção integral e da garantia de direitos humanos, a partir de um novo estado de exceção, destinado aos jovens considerados 'perigosos'pelo aparato médico-jurídico. 
4 De autoria da deputada fluminense Liliam Sá (PR/ RJ), o PL surge no exato momento em que nasce a carioca e polêmica Resolução SMAS no 20/2011, com a finalidade, entre outras, de propor o 'abrigamento compulsório' de crianças e adolescentes em situação de rua.
A classificação dos textos nessas categorias demonstra quão conservadora e de retrocesso é a maioria das proposições, voltadas a uma regulamentação de privações de direitos de adolescentes. A maioria dos PL apresenta tendência compatível com a doutrina da situação irregular e a lógica manicomial, com lastro em controle punitivo e institucionalizante. Em contraponto, sobressai apenas o PL $5.673 / 2009$, que proíbe a aplicação da medida privativa de liberdade nos casos de prática infracional resultante do uso de drogas.

No âmbito da 'medicalização da vida', as propostas dividem opiniões uma vez que algumas, apesar de se voltarem ao cuidado, reforçam a questionável tese do diagnóstico precoce de transtornos do desenvolvimento e da aprendizagem. É o caso do PL 7.081/2010, que obriga o poder público a

manter programa de diagnóstico e tratamento de estudantes da atenção básica com dislexia e Transtorno de Déficit de Atenção e Hiperatividade (TDAH). (BRASIL, 2010B),

bem como fornecer aos professores escolares curso sobre os diagnósticos. Semelhante é o PL 5.700/2009, que impõe às escolas a criação de ações de "avaliação e acompanhamento dos transtornos de aprendizagem” (BRASIL, 2009A). Ambos são questionáveis, ademais, porque visam instrumentalizar as escolas, substituindo-se, com isso, os serviços de saúde disponíveis ou demandáveis na comunidade, e aproximando os estabelecimentos educacionais das instituições totais. Destaca-se, em sentido distinto, o PLS 247/2012, que propõe que

o uso de psicofármacos em crianças e adolescentes exigirá comprovada necessidade do uso, que deve ocorrer em conformidade com os protocolos clínico-terapêuticos aprovados pelo Ministério da Saúde, proibindo o uso da medicalização de forma indiscriminada, inadequada, desnecessária ou excessiva. (BRASIL, 2012E).
Apresenta, portanto, a importância de fortalecer o papel dos órgãos de saúde na coordenação dos cuidados, especialmente pelas vias medicamentosas, com vista a frear os excessos desse processo, já que o Brasil, no decorrer da década de 2000, passou a figurar como o segundo país do mundo em prescrições de metilfenidato, genericamente conhecido como Ritalina ou Conserta, para diagnósticos de TDAH em crianças (HECKERT; ROCHA, 2012). Na mesma tendência dos dois primeiros projetos segueo PL 3.092/2012, eis que, embora não reduza os cuidados ao ambiente escolar, reforça a prática do cuidado medicamentoso pela "obrigatoriedade de fornecimento de medicamentos gratuitos pelo SUS para tratar Hiperatividade e TDHA em crianças portadoras da síndrome" (BRASIL, 2012C). Mais repressor é o PL 2372/2011, que impõe a "internação compulsória para tratamento de crianças e adolescentes, em situação de rua, dependentes de álcool e substâncias entorpecentes" (BRASIL, 2011B) ${ }^{4}$.

De modo geral, a medicalização da vida pode ser entendida como processo que torna contextos considerados problemáticos, de ordens diversas, em questões exclusivamente médicas, sendo retiradas do campo social de produção e restritasa processos biológicos próprios de cada indivíduo, sendo aquelas nomeadas como patologias a serem tratadas/curadas, prioritariamente, à base de medicamentos. Segundo Heckert e Rocha (2012), o não aprender, as inquietações ou agitações, conflitos e indisciplinas, geralmente expressas no ambiente escolar, quando individualizados e considerados 'anormais', têm como efeito a ampliação da jurisdição médica sobre problemas que, muitas vezes, emergem do chão da escola por meio de processos de patologização da diferença que anulam possibilidades de questionamento e reinvenção das instituições e contextos onde estão inseridas crianças e adolescentes. Nesse jogo de forças, em que comportamentos socialmente indesejados são reduzidos a problemas de cada um, são retirados do 
campo de análise atores e condições específicos que determinam os rumos das políticas da infância e da juventude, dentro ou fora da escola, a exemplo da indústria farmacêutica; do ritmo de trabalho dos pais exigido pelo sistema produtivo, dificultando-lhes o acompanhamento cotidiano de seus filhos; das condições de trabalho dos educadores; da mercantilização da educação, cada vez mais voltada para resultados pragmáticos etc.

Viu-se que, no contexto da 'responsabilização socioeducativa', os conteúdos dos PL são majoritariamente conservadores e de tendência retrógrada, dado o caráter punitivista e patologizante veiculado em seus textos. Em suma, 12 dos 13 PL apontam para a modificação da legislação da infância e adolescência no sentido da redução de direitos humanos de crianças e adolescentes. No que tange às ações de saúde mental em outras dimensões da vida desse público, com exceção do progressista PLC 30/2006, que dispõe sobre destinação, à política da infância, de recursos orçamentários oriundos de multas, os demais PL da categoria 'garantia de direitos' podem ser entendidos como desnecessários, haja vista que o investimento empregado em sua tramitação poderia ser direcionado para a fiscalização das leis e políticas em andamento, como visto, papel também precípuo dos parlamentares. Dos dez PL revelados na categoria 'proteção', por sua vez, seis também repetem normas proibitivas já compreendidas no ordenamento jurídico. Contraria apenas o PL 779/2003, que prevê a inclusão do conteúdo sobre uso de drogas no currículo escolar; e os presentes na 'medicalização da vida' tendem, em sua maioria, a fortalecer a lógica patologizante do comportamento infantil. Dos cinco PL em tela, apenas o PL 247/2012 propõe a desinstrumentalização psiquiátrica e psicológica das relações de sociabilidade infantil, enfrentando a tendência - que os demais PL assumem - de submeter, cada vez mais, os comportamentos infantoadolescentes a esses saberes.
É interessante perceber essas variações, muitas das quais sem fundamento teórico consistente, desconsiderando-se uma série de elementos contextuais socioculturais que compõem o ser criança e o ser adolescente. Vale ressaltar, especialmente nos PL de responsabilização, a ausência completa dos protagonistas da tríplice cooperação constitucional Estado, família e sociedade (art. 227 da Constituição Federal) entre os sujeitos e predicados alvos de demandas de cuidado em saúde. O foco da responsabilização está cada vez mais apontado para o próprio adolescente. Um exemplo que gera muitas inquietações sociais e se direciona ante uma responsabilização cada vez mais focada no adolescente se encontra no PL 192/2015, que problematiza a natureza pétrea da cláusula constitucional sobre a idade penal, apresenta argumentos descontextualizados, faz uso de comparações desproporcionais entre países e se arvora em argumentos pouco progressistas em uma perspectiva de redução de direitos, bem como da idade penal.

Ainda resta analisar os jogos de força a partir da participação de cada partido na propositura dos projetos de lei. Ao se pinçarem, brevemente, os PL cujos textos convergem com a legislação de saúde mental e de direitos de crianças e adolescentes - aqui nomeados como progressistas -, nota-se que são minoria expressiva e de autoria de parlamentares ligados, proporcionalmente, a partidos de esquerda.

\section{Análise das expressões partidárias em conexão com os eixos temáticos}

Entre os projetos voltados às ações em álcool e outras drogas, dos 106 PL, apenas 11 (11\%) têm caráter progressista, sendo majoritariamente de partidos de esquerda como PT, PDT e PSOL e, excepcionalmente, do PFL (PL 6520/06, que dispõe sobre ações de redução de danos) e do PMDB (PL 5298/16, que dá importância à responsabilidade civil do motorista que, nessa função, comete 
homicídio). De outro modo, os $89 \%$ restantes são de partidos de centro e de direita, justamente alguns dos quais, no atual governo federal de Michel Temer (PMDB/SP), protagonizam em base aliada.

No conjunto de 35 PL relacionados com a temática da infância e adolescência, 10 são de autoria de parlamentares filiados aos partidos de esquerda PT, PSB e PDT, porém somente os propostos na legenda do PT são de natureza progressista. Além desses, 3 PL progressistas são de autoria de parlamentares dos antigos PPB (PL 779/03) e PFL (PL 1.811/03) e do atual PMDB (PLC 30/06). Os demais $22 \mathrm{PL}$ (63\%) são de autoria de partidos de centro e de direita, como, em seu conteúdo, de retrocesso, pois divergem dos marcos de garantia de direitos das populações em pauta. Nesse sentido, $82 \%$ do total de PL em análise em ambos os eixos temáticos têm textos com finalidade de redução de direitos dos públicos-alvo, punitivistas ou de mera reiteração da legislação atual.

Em ambos os eixos, viu-se que, na segunda metade do período analisado, encontram-se os picos de produção legislativa, momento em que prevalece a natureza conservadora dos projetos. Os que mais chamam a atenção são os que cruzam os eixos analisados propondo medidas de caráter punitivista e patologizante a serem adotadas ao usuário de drogas, seja este criança, adolescente ou adulto. Como visto, a coincidência temporal - iniciada no ano de 2009 - entre o ápice das proposituras e o início dos programas de enfrentamento ao crack ganha legitimidade (e investimento orçamentário) no lançamento do programa 'Crack, é possível vencer', do Ministério da Justiça, em 2011. Em relação a esse ano, o orçamento decuplicou em 2014. Os discursos do cuidado e da repressão convivem na mesma agenda das drogas, vocalizados por todos os partidos, sem distinção. Ao mesmo tempo que se fortalecem os serviços substitutivos e territoriais, ganham força os espaços e práticas que retomam a lógica manicomial, a exemplo de clínicas psiquiátricas particulares, comunidades terapêuticas (CT) e internações compulsórias (STOCHERO; ARAÚJO; AHMED, 2013).

Exemplo dessa constatação, na categoria 'tratamento', do eixo Álcool e outras Drogas, e na categoria 'responsabilização socioeducativa', do eixo Infância e Juventude, encontra-se o caráter punitivista e patologizante do autor do delito ou de psiquiatrização da infração, em que são propostas internação compulsória e medida de segurança para os julgados pelo aparato médico-jurídico como 'perigosos', jovens e adolescentes que fazem uso de droga. Perante esses, as medidas propostas retomam o retrógrado pensamento lombrosiano, do final do século XIX, para o qual a 'delinquência' é uma expressão da doença mental, devendo esta ser controlada mais pela medicina psiquiátrica e menos pelo direito penal. São propostas que prescindem de prazo para a clausura, com o explícito desejo de punição mascarado pelo discurso da proteção. Todavia, além das modalidades sanitárias de punição para o tratamento dos 'desviantes', alguns projetos (PL 4.941/09 e PLS 2.27/09) prescindem do discurso médico patologizante e invocam o caráter punitivista a ser aplicado às respostas estatais a usuários de drogas, com a reinstituição da pena de prisão.

Por outro lado, dos poucos PL de natureza progressista, encontrados principalmente nas categorias 'prevenção e reabilitação', do eixo Álcool e outras Drogas, e 'garantia de direitos', do eixo Infância e Juventude, viu-se que a maioria propõe ações já estabelecidas nos normativos de saúde mental. Este dado sugere pensar que os serviços e programas já implementados não parecem funcionar à altura das demandas para as quais foram desenvolvidos, tornando-se invisibilizados como ações de prevenção de agravos e promoção dedireitos. Levanta-se a hipótese de que o crescente financiamento público de iniciativas privadas dos últimos cinco anos, destinado ao tratamento da população que faz uso de álcool e outras drogas, vem 
enfraquecendo os pontos de atenção já existentes, precarizando os equipamentos sociais de que se dispõem, embora muitos desses serviços privados caminhem na contramão dos princípios da autonomia, do cuidado em liberdade e em convivência familiar e comunitária. Como é o caso das CT, serviços atípicos de acolhimento, porque, além das violações daqueles direitos, caracterizam-se por realizar outras restrições em nome da abstinência em relação ao uso de drogas.

Ao mesmo tempo, a reiterada propositura do que já está disposto em normativos da saúde mental e da infância e juventude fortalece o papel legislador em detrimento das ações de fiscalização do poder executivo para o cumprimento da execução das políticas públicas, também inerente ao poder legislativo. Esse comportamento sugere que o comportamento parlamentar valoriza o interesse dos cidadãos a partir da criação de regras, a despeito de algumas delas já existirem e outras serem eventualmente danosas ao interesse público. Segundo Anastasia e Inácio (2010, p. 37), “o Poder Legislativo não está (ainda?) devidamente capacitado para exercer suas funções de monitoramento e avaliação dessas políticas", fragilidade que se explica pela dificuldade de instituir procedimentos indutores de responsabilidades cruzadas entre os governos subnacionais, mediante forte coordenação intergovernamental, além do investimento nas instâncias de participação política. Segundo os autores,

o monitoramento e a avaliação das políticas em cada nível de governo dependem de informações sobre as decisões e as ações levadas a cabo nos demais níveis. (ANASTASIA; INÁCIO, P. 42).

\section{Conclusão: perspectivas}

Para concluir o presente artigo, relacionaram-se os projetos de lei analisados e seus possíveis efeitos sobre a Política Nacional de Saúde Mental, Álcool e outras Drogas, mas também discorreu-se sobre alguns acontecimentos no âmbito do poder executivo que ensejaram ações específicas do poder legislativo no campo da saúde mental e que, após o processo de impeachment da Presidenta da República Dilma Rousseff, em 31 de agosto de 2016, poderão mobilizar outras disputas das políticas públicas em questão.

Em outubro de 2015, o então sanitarista ministro da saúde Arthur Chioro (PT/ SP) foi exonerado do cargo e, em seu lugar, assumiu o deputado federal Marcelo Castro (PMDB/PI). A entrega da pasta ao PMDB foi uma tentativa presidencial de garantir maior apoio político do majoritário partido perante as novas exigências da oposição, às vésperas do recebimento da denúncia que culminaria, dez meses depois, no impeachment da Presidenta da República. Efeito da mudança da chefia ministerial, dois meses depois, a exoneração do então gestor da Política Nacional de Saúde Mental, Roberto Tykanori, ensejou a nomeação do desconhecido Valencius Wurch, o que mobilizou sobremaneira os movimentos sociais ligados ao tema, a fim de evitar possíveis desmontes da Política Nacional (CORREIO, 2016).

Após 123 dias de ocupação da sala da Coordenação Nacional de Saúde Mental, Álcool e outras Drogas, manifestações e audiências públicas e reuniões institucionais com o governo federal (ABRASCO, 2016), os movimentos da luta antimanicomial priorizaram a interlocução com o poder legislativo, inicialmente na pessoa da deputada federal Erika Kokay (PT/DF). Nesse passo, com a presença de vários setores da Reforma Psiquiátrica, foi proposta a composição de uma Frente Parlamentar em Defesa da Reforma Psiquiátrica e da Luta Antimanicomial (HAJE, 2016), levada a cabo no 6 de abril, dia em que a lei respectiva completaria 15 anos. Seu planode trabalho pauta-se em ações de garantia do direito de ser cuidado nas redes de base comunitária, de não ser internado em hospital psiquiátrico e do direito de dele sair, em processos fielmente alinhados às 
diretrizes da Política Nacional, o que incidirá também na vida de crianças, adolescentes e pessoas com necessidades decorrentes do uso de drogas. Em suma, vale destacar que o plano é plenamente ilustrado de ações fiscalizatórias e contributivas ao poder executivo, bem como do acompanhamento dos PL ligados à Reforma Psiquiátrica e à Luta Antimanicomial (CÂMARA dos DePUTADOS, 2016). Sob coordenação da citada deputada, a Frente teve adesão de 198 deputados, dos quais 77 são membros de partidos classificados como de esquerda, o que expressa presença significativa contra os retrocessos nas respectivas políticas.

$\mathrm{Na}$ medida em que a democracia participativa constitui-se como alicerce do Estado Democrático de Direito, entende-se a Frente Parlamentar em Defesa da Reforma Psiquiátrica e da Luta Antimanicomial como um veículo do comportamento parlamentar de fiscal da administração pública, em audição de uma pauta em constante disputa social e institucional. Com isso, um dos efeitos pode ser a garantia da continuidade da política de saúde mental no modelo constitucional do SUS, a despeito do contexto em que se insere e se sustenta a maior parte dos PL analisados nos eixos Álcool e outras Drogas e Infância e Juventude. O esforço dessa e outras Frentes será hercúleo, na medida em que, no primeiro eixo, os $11 \mathrm{PL}$ de natureza progressista evidenciam a invertida do momento de ampliação de ações de cuidado e qualificação das políticas (primeira metade do período analisado) para um seguinte de acirramento do controle das liberdades e instalação de uma lógica penal-sanitarista (ASSIS, 2012) no campo das drogas (segunda metade do mesmo período). No segundo eixo, apesar de haver projetos de lei que apontam para pautas progressistas ( 5 dos 35), é complexo o cenário em que se encontra a saúde mental, pois, como discutiu-se, a lógica está cada vez mais patologizante e institucionalizante, desconectando-se, em uma crescente, das diretrizes do SUS. Nesses casos, os projetos de lei acabam por se tornar processos de instrumentalização legal que impactarão consideravelmente nos serviços, no processo de trabalho, no fazer profissional e no (possível não) cuidado com o usuário no âmbito da saúde mental.

Paralelamente aos acontecimentos políticos ocorridos no primeiro semestre de 2016, no campo da saúde mental, viu-se que o legislativo propôs predominantemente projetos de lei referentes às questões concernentes ao uso de álcool e outras drogas, os quais, em sua maioria, expressam o endurecimento de medidas punitivas e institucionalizantes travestidas de responsabilização. No âmbito executivo, mesmo após a exoneração de Wurche a do então ministro Castro, a Política de Saúde Mental, Álcool e outras Drogas continua desguarnecida, seja porque carece de gestor nomeado, seja em razão da postura do novo ministro, o deputado federal Ricardo Barros (PP/PR).

Sem guarida, a política de saúde mental pode ser alvo de negociações desde que $o$ deputado federal Osmar Terra (PMDB/ RS) assumira a chefia do Ministério do Desenvolvimento Social e Agrário (MDSA), em virtude da sua relação com o campo das drogas. Terra tem um emblemático Projeto de Lei ( $n^{\circ} 7.663 / 2010$, atual PLC 37/2013), já citado, que prevê a alteração mais ampla, austera e conservadora da nova lei de drogas, da Lei $\mathrm{n}^{\mathrm{o}} 10.216 / 2001$ e das modalidades de cuidado instituídos pelos SUS, Sistema Único de Assistência Social (Suas), e Sistema Nacional de Políticas sobre Drogas (Sisnad), o que se expressa na regulamentação de comunidades terapêuticas. Nessa crescente incidência, para lhe assessorar no MDSA, Terra nomeou como secretário executivo o ex-secretário de atenção à saúde de Marcelo Castro, Alberto Beltrame, proprietário de clínicas dessa natureza, em uma das quais é sócio do suplente de Ronaldo Laranjeiras no Conselho Nacional de Políticas sobre Drogas (Conad), psiquiatra expoente na defesa de modalidade de tratamento semelhante à empregada nas 
comunidades terapêuticas. Ato contínuo, em posições máximas no MDSA, ambos se nomearam membros do Conad.

Em suma, as disputas perduram no entorno da Política Nacional de Saúde Mental e da jovem política de drogas. No período de 14 anos de análise, além do variado acervo de PL e da dança das cadeiras ministeriais com notável alteração nos últimos 16 meses, estando partidos de centro e direita na chefia do Ministério da Saúde -, percebe-se que a emergência das Frentes Parlamentares também redimensiona o cenário legislativo em torno das políticas em pauta. Em novembro de 2015, reinaugurou-se a Frente Parlamentar Mista em Defesa da Criança e do Adolescente, com 87 deputados de partidos classificados como de esquerda, entre 202 membros. A Frente Parlamentar em Defesa dos Direitos Humanos, inaugurada em maio de 2015, conta com 217 parlamentares, dos quais 98 representam partidos de esquerda. Comum atribuição das Frentes, o acompanhamento e monitoramento das proposições legislativas no entorno de seu respectivo tema evidencia a importância que carrega o papel de fiscalizador das políticas públicas.

Em termos conjunturais, vislumbra-se um cenário complexo de disputa não mais por leis em branco, à espera de anotações - como se deu até os anos 1990 -, mas de leis em vigência, que, apesar da consolidação dos sistemas sociais, sustentam políticas que podem sofrer atrasos e reformulações pela nova compleiçãofederal, composta de parlamentares de partidos de direita e centro, signatários do majoritário rol de PL conservadores. Do outro lado da disputa, encontram-se os parlamentares de partidos de esquerda, notórios constituintes da base aliada em quase todo o período de análise. Esses, ao mesmo tempo que, a partir do impeachment, perdem voz no poder executivo, parecem se destinar a fortalecer instrumentos de defesa da política de saúde mental no âmbito legislativo.

\section{Colaboradores}

Daniel Adolpho e Alyne Alvarez contribuíram substancialmente para a concepção e o planejamento e para a análise e interpretaçãodos dados; bem como para a elaboração do rascunho e revisão crítica do conteúdo. Ticiana Torres contribuiu substancialmente para o planejamento e para a sistematização dos dados; bem como para a elaboração do rascunho. Todos participaram da aprovação da versão final do manuscrito. 


\section{Referências}

ANASTASIA, F.; INÁCIO, M. Democracia, Poder Legislativo, interesses e capacidades. Cadernos ASLEGIS40. 2010.Disponível em: <https://www.ufpe. br/politica/images/pdf/aslegis.pdf >. Acesso em: 10 set. 2016.

ASSIS, D. A. D. Risco social e saúde mental como argumentos para o encarceramento de crianças e adolescentes. 2012. 179 f. Dissertação (Mestrado profissional em Adolescência em Conflito com a Lei) - Universidade Bandeirante de São Paulo, São Paulo, 2012.

ASSIS, D. A. D.; SILVA, A. A. O impacto do Sistema Nacional de Políticas Públicas sobre Drogas na aplicação de medida de segurança, à luz da Convenção sobre os Direitos da Pessoa com Deficiência. In: MIGUEL, V. V. R; KALHED JR, S. H. Direitos fundamentais na era dos extremos: a exceção como regra. Florianópolis: Empório do Direito, 2016. p. 155-181.

\section{ASSOCIAÇÃO BRASILEIRA DE SAÚDE COLETIVA}

(ABRASCO). Mídia repercute (L)Oucupa Brasília e luta antimanicomial define novas estratégias. Disponível em: <https://www.abrasco.org.br/site/2016/01/midia-repercute-loucupa-brasilia-e-luta-antimanicomial-define-novas-estrategias/>. Acesso em: 10 set. 2016.

BAPTISTA, T. W. F. Políticas de saúde no pós-constituinte: um estudo da política implementada a partir da produção normativa dos poderes executivo e legislativo no Brasil. 2003. 346 f. Tese (Doutorado em Saúde Coletiva) - Instituto de Medicina Social, Universidade Estadual do Rio de Janeiro, Rio de Janeiro, 2003.

BRASIL. Constituição da República Federativa do Brasil, 1988. Disponível em: <http://www.planalto.gov.br/ ccivil_03/Constituicao/Constituicao.htm>. Acesso em: 10 set. 2016

Câmara dos Deputados. Projeto de Lei PL 7.270/2014. Regula a produção, a industrialização e a comercialização de Cannabis, derivados e produtos de Cannabis, dispõe sobre o Sistema Nacional de Políticas Públicas sobre Drogas, cria o Conselho Nacional de Assessoria, Pesquisa e Avaliação para as Políticas sobre
Drogas, altera as leis nos 11.343, de 23 de agosto de 2006, 8.072, de 25 de julho de 1990, e 9.294, de 15 de julho de 1999 e dá outras providências. 2014a. Disponível em: <http://www.camara.gov.br/proposicoesWeb/fich adetramitacao?idProposicao=608833>. Acesso em: 10 set. 2016.

Câmara dos Deputados. Projeto de Lei PL 7.187/2014. Dispõe sobre o controle, a plantação, o cultivo, a colheita, a produção, a aquisição, o armazenamento, a comercialização e a distribuição de maconha (cannabis sativa) e seus derivados, e dá outras providências. 2014b. Disponível em: <http://www.camara. gov.br/proposicoesWeb/fichadetramitacao?idProposic $\mathrm{ao}=606843>$. Acesso em: 10 set. 2016.

Câmara dos Deputados. Projeto de Lei PL 5.700/2009. Acrescenta alínea ao art. 24, V, da Lei n ${ }^{\circ}$ 9.394, de 20 de dezembro de 1996, que estabelece as diretrizes e bases da educação nacional. 2009a. Disponível em: <http://www.camara.gov.br/proposicoesWeb/fichadetramitacao?idProposicao $=443750>$. Acesso em: 10 set. 2016.

Câmara dos Deputados. Projeto de Lei PL 6874/2010. Altera a Lei no 9.394 de 1996, que estabeleceu Diretrizes e Bases da Educação. Explicação: Garante a criação de núcleo psicossocial nas escolas públicas de ensino fundamental para atendimento às vítimas de violência doméstica, maus tratos e dependência química. 2010a. Disponível em: <http://www. camara.gov.br/proposicoesWeb/fichadetramitacao?idP roposicao=467579>. Acesso em: 10 set. 2016.

Câmara dos Deputados. Projeto de Lei PL 7.081/2010. Dispõe sobre o diagnóstico e o tratamento da dislexia e do Transtorno do Deficit de Atenção com Hiperatividade na educação básica. 2010b. Disponível em: <http://www.camara.gov.br/proposicoesWeb/fich adetramitacao?idProposicao $=472404>$. Acesso em: 10 set. 2016.

Câmara dos Deputados. Projeto de Lei PL 1.052/2011. Altera a Lei no 8.069, de 13 de julho de 1990 - Estatuto da Criança e do Adolescente - para 
ampliar o prazo de internação do adolescente infrator, estabelecer a possibilidade de aplicação de medidas de segurança, e dá outras providências. 2011a. Disponível em: <http://www.camara.gov.br/proposicoesWeb/fich adetramitacao?idProposicao $=498429>$. Acesso em: 10 set. 2016.

. Câmara dos Deputados. Projeto de Lei PL

2.372/2011. Acrescenta o inciso X ao art. 101 e o art. 101-A à Lei no 8.069, de 13 de julho de 1990, que “dispõe sobre o Estatuto da Criança e do Adolescente e dá outras providências”. 2011b. Disponível em: <http://www. camara.gov.br/proposicoesWeb/fichadetramitacao?idP roposicao $=520720>$. Acesso em: 10 set. 2016.

Câmara dos Deputados. Projeto de Lei PL

4.767/2012. Altera a Lei $n^{\circ} 8.069$, de 13 de julho de 1990 (Estatuto da Criança e do Adolescente), para garantir assistência integral e multiprofissional à criança e ao adolescente dependentes químicos e/ou com problemas decorrentes do uso de drogas. 2012a. Disponível em: <http://www.camara.gov.br/proposicoesWeb/fic hadetramitacao?idProposicao $=561295>$. Acesso em: 10 set. 2016.

Câmara dos Deputados. Projeto de Lei PL

$3.121 / 2012$. Concede incentivo fiscal às entidades desportivas da modalidade futebol que instituírem programas de recuperação de jovens drogados ou desempregados, mediante capacitação técnica ou profissional, ou atendimento médico, psicológico e social. 2012b. Disponível em: <http://www.camara.gov.br/proposicoesWeb/fichadetramitacao?idProposicao=533885>. Acesso em: 10 set. 2016.

Câmara dos Deputados. Projeto de Lei PL 3.092/2012. Que dispõe sobre a obrigatoriedade de fornecimento de medicamentos gratuito pelo SUS para tratar Hiperatividade e TDHA em crianças portadoras da síndrome sem distinção de classe, nem mesmo aqueles pacientes que não se enquadram como os mais carentes poderão ser excluídos do benefício. 2012c. Disponível em: <http://www.camara.gov.br/proposicoesWeb/fichadetramitacao?idProposicao=533790>. Acesso em: 10 set. 2016.

Câmara dos Deputados. Projeto de Lei PL
1.795/2015. Altera a Lei no 8.069, de 13 de julho de 1990 - Estatuto da Criança e do Adolescente, para tornar crime vender, fornecer, servir, ministrar ou entregar bebida alcoólica e energética a criança ou a adolescente. Disponível em: <http://www.camara.gov.br/proposicoesWeb/fichadetramitacao?idProposicao=1301761 > 2015a. Acesso em: 10 set. 2016.

\section{Câmara dos Deputados. Projeto de Lei PL} 2.116/2015. Altera o Decreto-Lei no 2.848, de 7 de dezembro de 1940 (Código Penal), a Lei no 8.069, de 13 de julho de 1990 (Estatuto da Criança e do Adolescente), e a Lei ${ }^{\circ} 12.594$, de 18 de janeiro de 2012 (Institui o Sistema Nacional de Atendimento Socioeducativo - Sinase), para dispor sobre a responsabilização de adolescentes por atos infracionais, e dá outras providências.2015b. Disponível em: <http://www. camara.gov.br/proposicoesWeb/fichadetramitacao?idP roposicao $=1537470>$. Acesso em: 10 set. 2016.

Câmara dos Deputados. Projeto de Lei PL 1.325/2015. Altera dispositivos na Lei ${ }^{\circ}$ 8.069, de 13 de julho de 1990, e dá outras providências. 2015c. Disponível em: <http://www.camara.gov.br/proposicoesWeb/fichadetramitacao?idProposicao=1227888 >. Acesso em: 10 set. 2016.

Câmara dos Deputados. Projeto de Lei PL $5.705 / 2016$. Altera a Lei no 8.069 , de 13 de julho de 1990, que "Dispõe sobre o Estatuto da Criança e do Adolescente e dá outras providências”, para dispor sobre o cuidado com a saúde mental dos menores infratores submetidos ao regime de internação, e dá outras providências. 2016a. Disponível em: < http://www. camara.gov.br/proposicoesWeb/fichadetramitacao?idP roposicao=2089686 . Acesso em: 10 set. 2016 .

Lei no 8.069, de 13 de julho de 1990. Dispõe sobre o Estatuto da Criança e do Adolescente e dá outras providências. Diário Oficial [da] União, Brasília, DF, 14 jul. 1990a. Disponível em: <http://www.planalto.gov. br/ccivil_03/leis/L8069.htm>. Acesso em: 10 set. 2016.

Lei no 8.080 , de 19 de setembro de 1990. Dispõe sobre as condições para a promoção, proteção e recuperação da saúde, a organização e o funcionamento dos serviços correspondentes e dá outras providências. 
Diário Oficial [da] União, Brasília, DF, 20 set. 1990b. Disponível em: <http://www.planalto.gov.br/ccivil_03/ leis/L8080.htm>. Acesso em: 10 set. 2016.

Lei $\mathrm{n}^{\circ}$ 10.216, de 06 de abril de 2001. Dispõe sobre a proteção e os direitos das pessoas portadoras de transtornos mentais e redireciona o modelo assistencial em saúde mental. Diário Oficial [da] União, Brasília, DF, 7 abr. 2001. Disponível em: <http://www.planalto. gov.br/ccivil_03/leis/LEIS_2001/L10216.htm>. Acesso em: 10 set. 2016

Lei ${ }^{\circ} 11.343$, de 23 de agosto de 2006. Institui o Sistema Nacional de Políticas Públicas sobre Drogas - Sisnad; prescreve medidas para prevenção do uso indevido, atenção e reinserção social de usuários e dependentes de drogas; estabelece normas para repressão à produção não autorizada e ao tráfico ilícito de drogas; define crimes e dá outras providências. Diário Oficial [da] União, Brasília, DF, 24 ago. 2006. Disponível em: <http://www.planalto.gov.br/ccivil_03/_ato20042006/2006/lei/111343.htm>. Acesso em: 10 set. 2016.

Ministério da Saúde. Portaria GM/MS nº 1.190, de 04 de junho de 2009. Institui o Plano Emergencial de Ampliação do Acesso ao Tratamento e Prevenção em Álcool e outras Drogas no Sistema Único de Saúde SUS (PEAD 2009-2010) e define suas diretrizes gerais, ações e metas. Diário Oficial [da] União, Brasília, DF, 05 jun. 2009a. Disponível em: <http://bvsms.saude. gov.br/bvs/saudelegis/gm/2009/prt1190_04_06_2009. html>. Acesso em: 10 set. 2016.

Ministério da Saúde. Portaria GM/MS n ${ }^{\circ}$ 3.088, de 23 de dezembro de 2011. Institui a Rede de Atenção Psicossocial para pessoas com sofrimento ou transtorno mental e com necessidades decorrentes do uso de crack, álcool e outras drogas, no âmbito do Sistema Único de Saúde (SUS). Diário Oficial [da] União, Brasília, DF, 24 dez. 2011c. Disponível em: <http://bvsms.saude.gov.br/bvs/saudelegis/gm/2011/ prt3088_23_12_2011_rep.html>. Acesso em: 10 set. 2016.

Ministério da Saúde. Portaria GM/MS nº 1.482, de 04 de agosto de 2016. Institui Grupo de Trabalho para discutir projeto de Plano de Saúde Acessível. Diário Oficial [da] União, Brasília, DF, 5 ago. 2016b.
Disponível em: <http://pesquisa.in.gov.br/impren$\mathrm{sa} /$ jsp/visualiza/index.jsp?jornal=1\&pagina $=26 \& \mathrm{da}$ ta $=05 / 08 / 2016>$. Acesso em: 10 set. 2016.

Ministério da Saúde. Saúde Mental em Dados, v. 7, n. 11, Brasília, DF, 2012c. Disponível em:<http://psiquiatriabh.com.br/wp/wp-content/uploads/2015/01/ Dados-da-rede-assistencial-brasileira-2012-Ministerioda-Saude.pdf>. Acesso em: 10 set. 2016.

Senado Federal. Projeto de Lei do Senado PLS 67/2009. Altera os arts. 28 e 29 da Lei n ${ }^{\circ} 11.343$, de 23 de agosto de 2006, para reforçar a punição prevista para o consumo pessoal de drogas com a imposição cumulativa da pena de multa. 2009b. Disponível em: <http:// www25.senado.leg.br/web/atividade/materias/-/materia/89731>. Acesso em: 10 set. 2016.

Senado Federal. Projeto de Lei do Senado PLS 227/2009. Altera o art. 28 da Lei no 11.343 , de 23 de agosto de 2006, para prever pena de detenção para condutas relacionadas ao consumo pessoal de droga. 2009c. Disponível em: <http://www25.senado.leg.br/ web/atividade/materias/-/materia/91338>. Acesso em: 10 set. 2016.

Senado Federal. Projeto de Lei do Senado PLS 408/2011. Altera a Lei no 8.069, de 13 de julho de 1990, que dispõe sobre o Estatuto da Criança e do Adolescente e dá outras providências, para garantir tratamento especial ao adolescente viciado em drogas. 2011d. Disponível em: <http://www25.senado.leg.br/ web/atividade/materias/-/materia/101220>. Acesso em: 10 set. 2016 .

Senado Federal. Projeto de Lei do Senado PLS 23/2012. Altera a Lei no 8.069, de 13 de julho de 1990 - Estatuto da Criança e do Adolescente e a Lei ${ }^{\circ}$ 12.594, de 18 de janeiro de 2012, que institui o SINASE Sistema Nacional de Atendimento Socioeducativo, para prever nova modalidade de medida socioeducativa e dá outras providências. 2012d. Disponível em: <http:// www25.senado.leg.br/web/atividade/materias/-/materia/104268>. Acesso em: 10 set. 2016.

Senado Federal. Projeto de Lei do Senado PLS 247/2012. Altera a Lei no 8.069, de 13 de julho de 
1990, que dispõe sobre o Estatuto da Criança e do Adolescente e dá outras providências, para instituir medidas destinadas à prevenção do uso inadequado de psicofármacos em crianças e adolescentes. 2012e. Disponível em: <http://www25.senado.leg.br/web/ atividade/materias/-/materia/106495>. Acesso em: 10 set. 2016.

Senado Federal. Projeto de Lei do Senado PLS 285/2012. Altera o art. 33 da Lei $n^{\circ} 11.343 / 2006$ para incluir no crime de Tráfico e consumo de drogas ilícitas as condutas de comprar, adquirir e consumir em local público. Dispõe que o juiz, na fixação da pena, considerará o potencial lesivo à saúde e a quantidade de droga apreendida. Disciplina que na hipótese de pequena quantidade da droga apreendida, que permita inferir que se destinava apenas a consumo pessoal, levando-se em consideração a natureza da droga, o local e as circunstâncias da apreensão, assim como os antecedentes e a conduta social do agente, o juiz deixará de aplicar a pena se o agente aceitar sujeitar-se a tratamento especializado em estabelecimento público de saúde, a ser escolhido pelo juiz. 2012f. Disponível em: <http:// www25.senado.leg.br/web/atividade/materias/-/materia/106806>. Acesso em: 10 set. 2016.

\section{CÂMARA DOS DEPUTADOS. Lançamento da Frente} Parlamentar em Defesa da Reforma Psiquiátrica e da Luta Antimanicomial. Disponível em: <https://gaming:youtube. $\mathrm{com} /$ watch?v=mV3BgmSQXXc\&list=PLbO0ECxK9V-cXzRnMEkuq9LVZuljNXEI1>. Acesso em: 10 set. 2016.

CHAIB, J. Troca de nomes para gestão da política de psiquiatria provoca reação. Correio Brasiliense, Brasília, DF, 14 de dezembro de 2015. Disponível em: <http://www.correiobraziliense.com.br/app/noticia/ brasil/2015/12/14/internas_polbraeco,510561/troca-de-nomes-para-gestao-da-politica-de-psiquiatria-provoca-reacao.shtml>. Acesso em: 10 set 2016.

\section{CONSELHO NACIONAL DOS DIREITOS DA} CRIANÇA E DO ADOLESCENTE (CONANDA). Resolução ${ }^{\circ}$ 117, de 11 de julho de 2006. Diário Oficial [da] União, Brasília, DF, 12 jul. 2006. Disponível em: <http://dh.sdh.gov.br/download/resolucoes-conanda/ res-117.pdf >. Acesso em: 10 set. 2016.
CORREIO BRAZILIENSE. Há cem dias, movimento antimanicomial acampa em sala do Ministério da Saúde. Disponível em: <http://www.correiobraziliense.com. br/app/noticia/brasil/2016/03/21/internas_polbraeco,523178/ha-cem-dias-movimento-antimanicomial-acampa-em-sala-do-ministerio-da-s.shtml>. Acesso em: 10 set. 2016

FONSECA, E. J. O papel do Poder Legislativo na construção do Sistema Único de Saúde: a Frente Parlamentar da Saúde e a regulamentação da Emenda à Constituição $n^{\circ} 29.200880$ f. Monografia (Especialização instituições e Processos Políticos do Legislativo) - Câmara dos Deputados, Centro de Formação, Brasília, DF, 2008. Disponível em: <http://bd.camara.gov.br/bd/handle/ bdcamara/685>. Acesso em: 1 fev. 2017.

\section{FÓRUM NACIONAL SOBRE MEDICALIZAÇÃO DA} EDUCAÇÃO E DA SOCIEDADE. MEC envia recomendações do MS para adoção de práticas não medicalizantes. Disponível em: <http://medicalizacao.org.br/>. Acesso em: 20 set. 2016.

FOUCAULT, M. Nascimento da Biopolítica. São Paulo: Martins Fontes, 2008.

HAJE, L. Frente em Defesa da Reforma Psiquiátrica e da Luta Antimanicominal é lançada na Câmara. Agência Câmara Notícias. Disponível em: <http:// www2.camara.leg.br/camaranoticias/noticias/ SAUDE/506532-FRENTE-EM-DEFESA-DAREFORMA-PSIQUIATRICA-E-DA-LUTAANTIMANICOMINAL-E-LANCADA-NA-CAMARA. html>. Acesso em: 10 set. 2016.

HECKERT, A. L. C.; ROCHA, M. L. A maquinaria escolar e os processos de regulamentação da vida. Psicologia \&t Sociedade, Belo Horizonte, v. 24, n. esp., p. 85-93. 2012.

\section{OBSERVATÓRIO DE ANÁLISE POLÍTICA EM}

SAÚDE. Análise de políticas de saúde no Brasil (2013 - 2017). Disponível em: <http://www.analisepoliticaemsaude.org/oaps/quem-somos/1/>. Acesso em: 10 set. 2016 . 
STOCHERO, T.; ARAÚJO, G.; AHMED, M. Governo libera R\$ 738 milhões sem conhecer 'epidemia' de crack. G1. São Paulo, 2 jan. 2013. Disponível em: <http:// gl.globo.com/brasil/noticia/2013/01/governo-libera-r-738-milhoes-sem-conhecer-epidemia-de-crack. html>. Acesso em: 10 set. 2016.

VASCONCELOS, F. Maioria dos partidos se posiciona como de centro. O Globo. Brasília, DF, 29 mar. 2016. Disponível em: <http://blogs.oglobo.globo.com/na-base-dos-dados/post/maioria-dos-partidos-se-posiciona-como-de-centro-veja-quem-sobra-no-campo-da- -direita-e-da-esquerda.html>. Acesso em: 10 set. 2016.

Recebido para publicação em outubro de 2016

Versão final em fevereiro de 2017

Conflito de interesses: inexistente

Suporte financeiro: Pesquisa financiada pelo CNPq e Ministério da Saúde (Chamada MCTI / CNPq / CT-Saúde / MS / SCTIE / Decit no 41/2013) 